\title{
Discovery and geological significance of the Magma-hydrothermal micro-jets at the bottom of a lake: A case from the Chang 7 section of
} the Yanchang Formation of the Triassic in the Ordos Basin, China

You Ji-yuan1,2, Liu Yi-qun1, Zhou Ding-wu3

1.State Key Laboratory of Continental Dynamics,Department of Geology,Northwest University,Xi'an 710069, China

2.School of Energy Engineering, Yulin University,Yulin 719000,China

3.College of Earth Science and Engineering,Shandong University of Science and Technology, Qingdao 266510, China

The first author: You Jiyuan, male, 1985, PhD student, mainly engaged in hydrothermal sedimentology research.Email:2373375337@qq.com

Address: Office 405, Department of Geology, Northwest University, 229 Taibai North Road, Beilin District, Xi'an, China,710069,Tel:18717661715

\begin{abstract}
The "black chimney" type of hydrothermal vents in the modern deep sea have become a popular research topic in many disciplines. Due to the actual conditions, the research on palaeo-thermal vents in geological history is relatively low. Fortunately, the discovery of hydrothermal vents and bio-fossils from the Chang 7 source rocks of the Yanchang Formation of the Triassic in the Ordos Basin, China, provides the best evidence for deciphering hydrothermal activity during geological history. Here, we report a case study. Through ordinary sheet observation, scanning electron microscopy and electron probe observation, layered grained siliceous rocks, dolomites, and hydrothermal mineral combinations, such as pyrite + dolomite + gypsum and calcite + barite, are found. Their unique petrological characteristics, mineral composition, and structure confirm the existence of palaeo-thermal fluid vents. We further analysed the geochemical characteristics and in situ isotope characteristics. The study found that $\mathrm{Cs}, \mathrm{U}, \mathrm{Th}, \mathrm{Pb}, \mathrm{Ba}$ and other trace elements of the sample showed positive abnormalities, in which values of U/Th were high; in addition, the enrichment of major elements such as $\mathrm{Sr}, \mathrm{Mn}$, and the in situ sulphur isotopes of pyrite reached $7.89 \%-10.88 \%$. This study of hydrothermal vents over geological history is expected to provide new insights on the life forms of various extreme microorganisms in hydrothermal environments and on their formation of high-quality source rocks.
\end{abstract}

Keywords: hydrothermal channel, hydrothermal vent, extreme environment, Triassic, Ordos Basin 


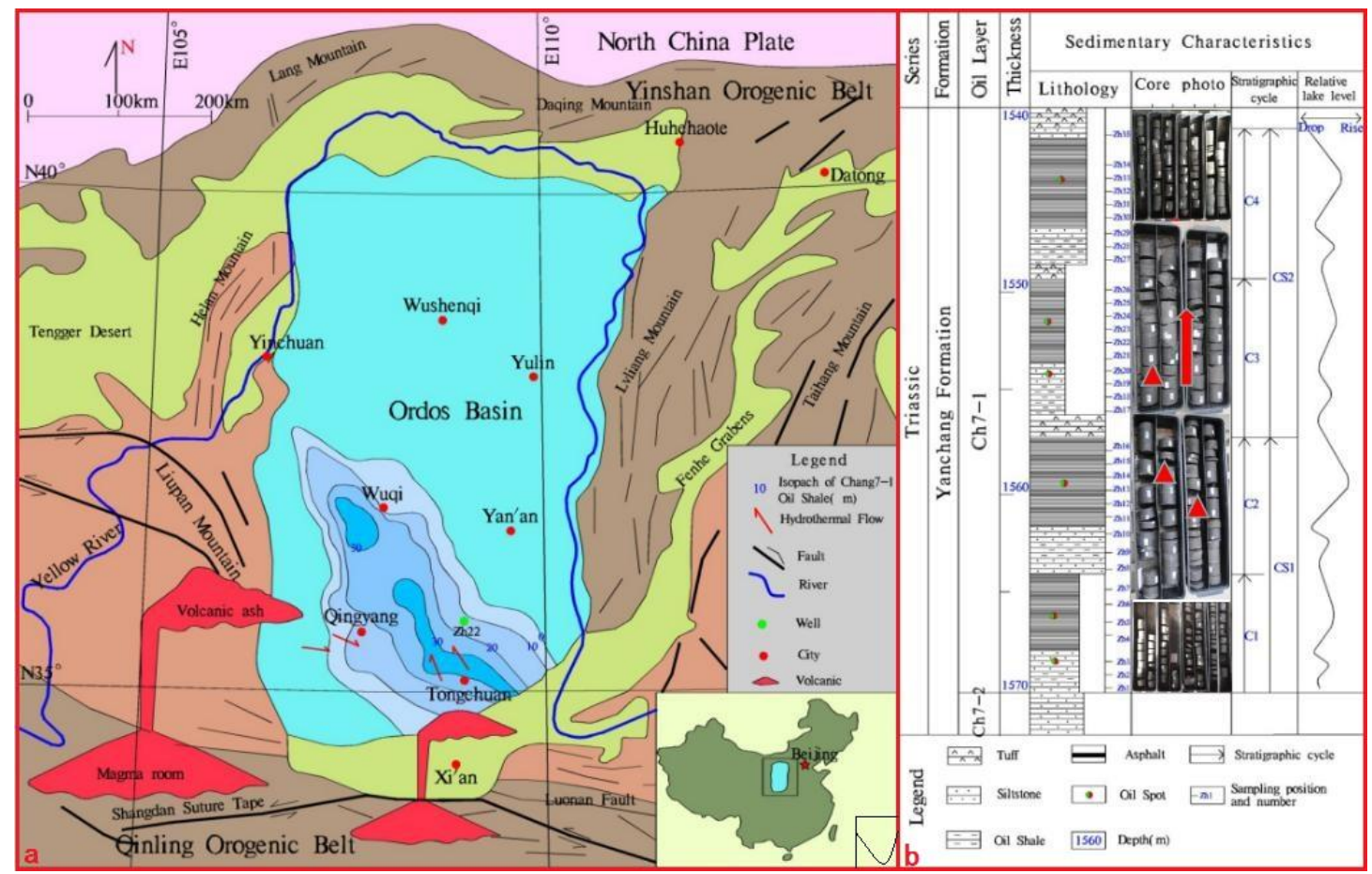

Fig. 1 Regional geological map of the Ordos Basin (a) and map of the stratigraphic column and sampling position (b)

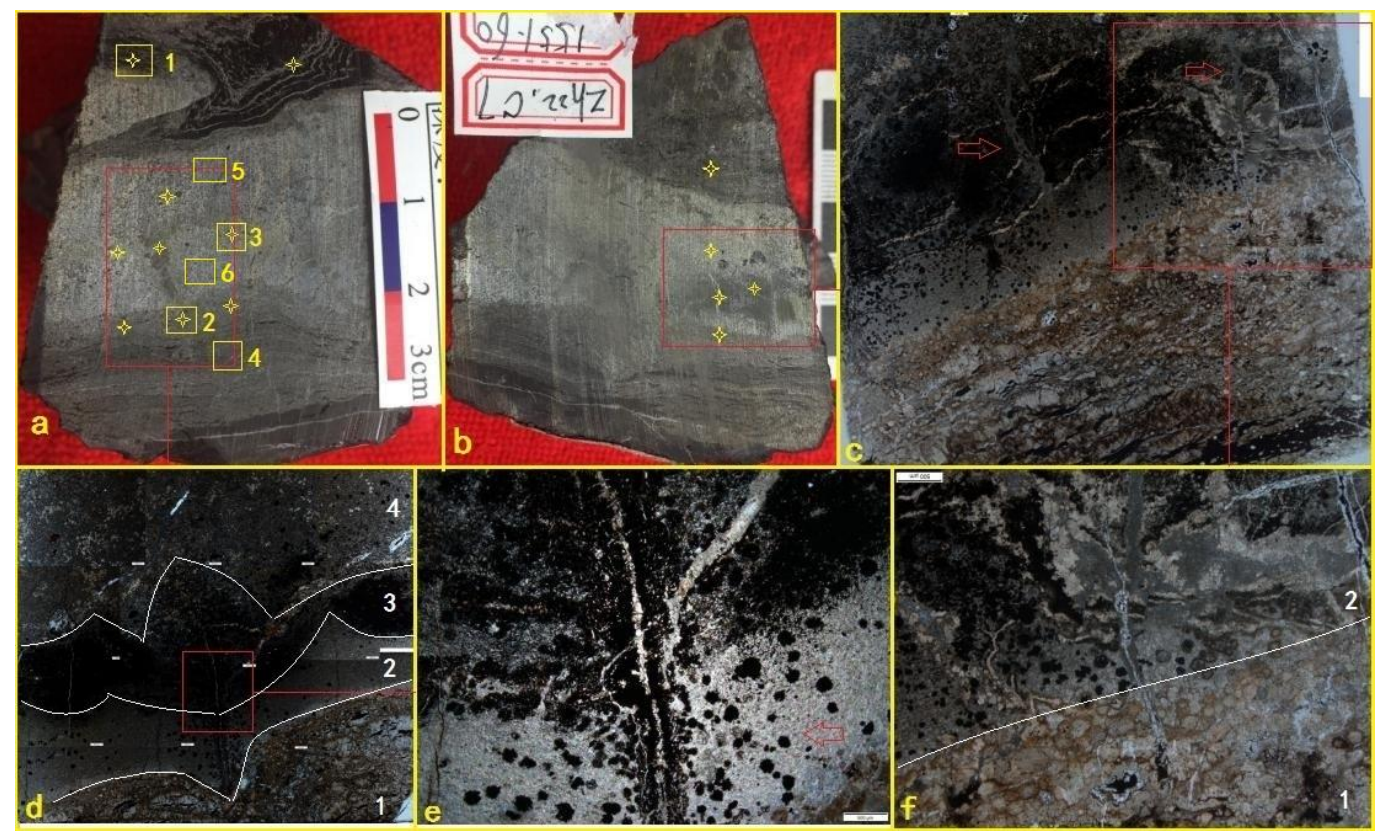

Fig. 2 Characteristics of hydrothermal micro-jets in the study area

a. Hydrothermal micro-spray, $5 \mathrm{~cm} \times 3 \mathrm{~cm}$, sample NO. 1551.6 .

b. Hydrothermal micro-spray, $5 \mathrm{~cm} \times 3 \mathrm{~cm}$, sample NO. 1551.6-2.

c. Enlargement photo of the red frame in picture $b$, in which we can identify 2 micro-sprays, at $2.5 \times$ times magnification, with orthogonal light.

d. Enlargement photo of the red frame in picture a, in which layer 1 is a dolomite with a radial structure; layer 2 is calcite; layer 3 is a pyrite layer; layer 4 is calcite + dolomite + anhydrite + siliceous rock; at $2.5 \times$ times magnification, with orthogonal light. 
e. Enlargement photo of the red frame in picture d, in which the jet channel is filled with calcite,

iron dolomite, and siliceous rock; the black mineral is Py, which naturally falls during the eruption; at $2.5 \times$ times magnification, with orthogonal light.

f. Enlargement photo of the red frame in picture c, in which layer 1 is a dolomite with radial structure and layer 2 is calcite + pyrite + siliceous rock; at $2.5 \times$ times magnification, with orthogonal light.

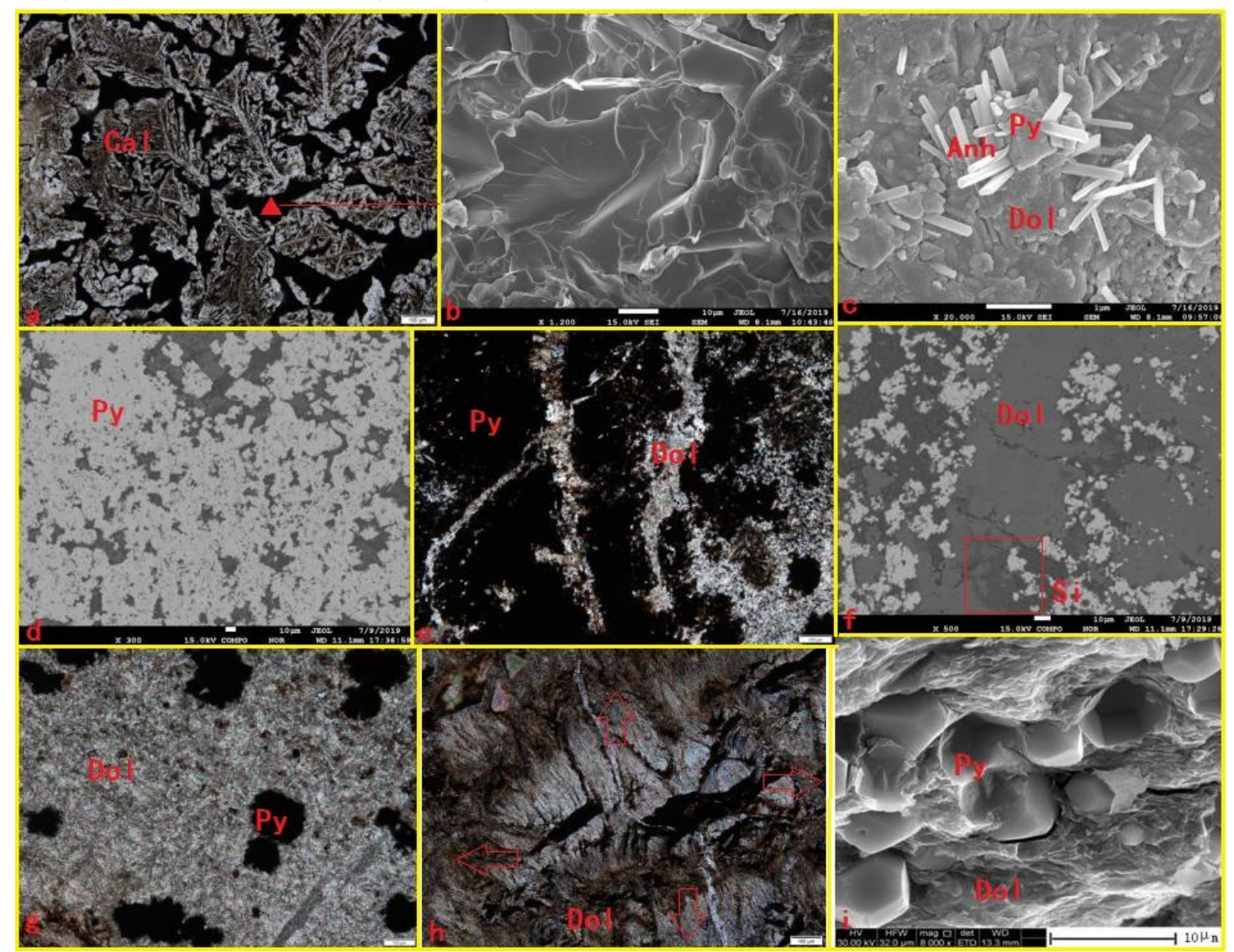

Fig. 3 Fig. 3 Mineralogy and structural characteristics of hydrothermal micro-jets.

A Picture $2 \mathrm{a} 1$ of the yellow frame photo, calcite, at $10 \times$ times, with orthogonal light.

B SEM image of the triangle position of Fig. $3 \mathrm{a}$.

C Picture $2 \mathrm{a} 5$ of the yellow frame photo, pyrite + dolomite + anhydrite, with SEM.

$\mathrm{d}$ Picture $2 \mathrm{a} 3$ of the yellow frame photo, pyrite, with BSE.

e Photograph $2 \mathrm{a} 1$ of the yellow frame photo, jet channel structure, at $10 \times$ times magnification, with orthogonal light.

f Picture 2al of the yellow frame photo, jet channel structure, with BSE.

G Photograph $2 \mathrm{a} 6$ of the yellow frame, pyrite particles fall naturally, at $10 \times$ times magnification, with orthogonal light.

h Picture 2a4 yellow frame photo, radial structure, at 10× times magnification, with orthogonal light.

i Fig. 3d SEM photo of pyrite. 


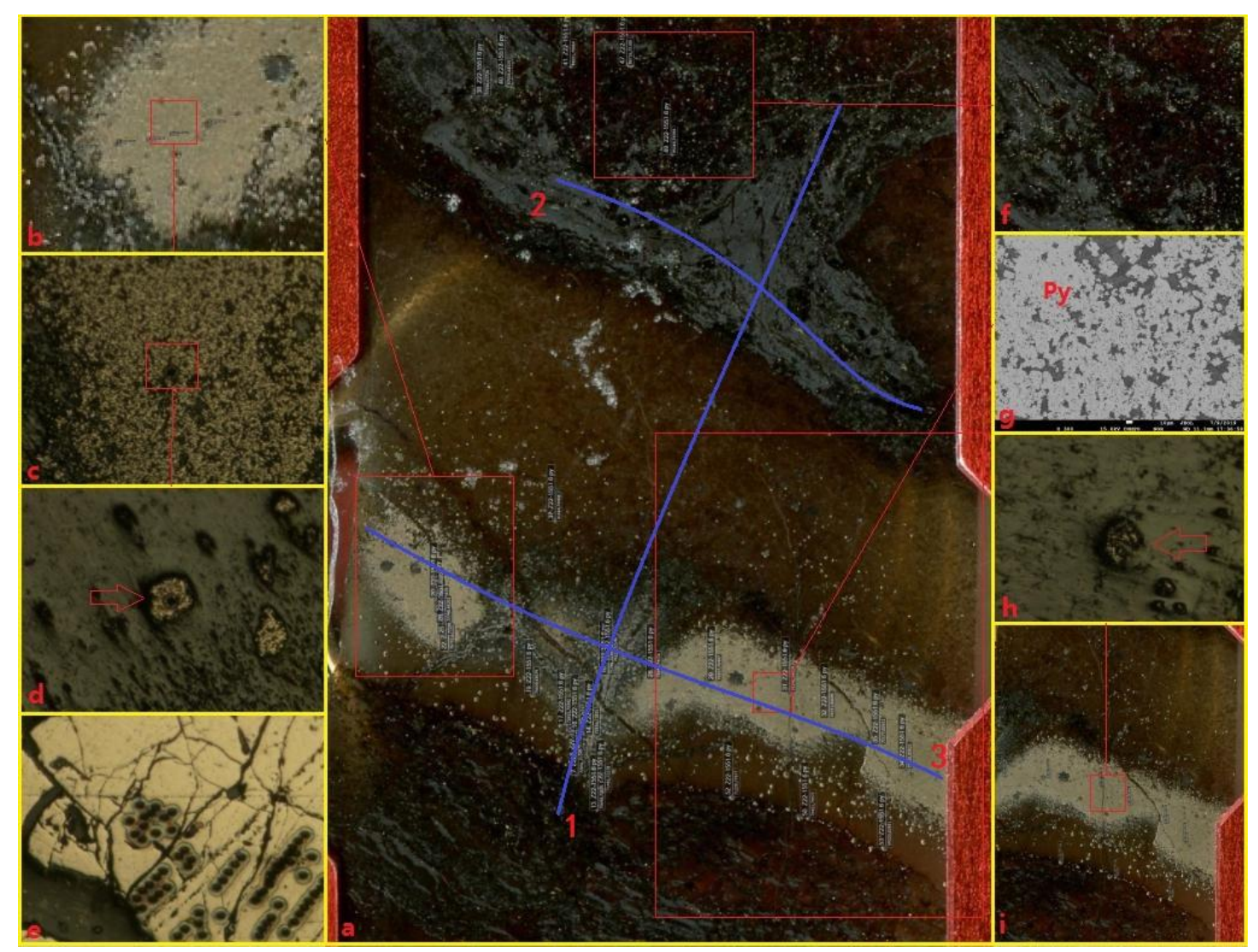

Fig. 4 Analysis point of in situ trace elements and sulphur isotopes around pyrite of the hydrothermal micro-jet

a. Macroscopic photograph of the hydrothermal vent and experimental point, where the three blue lines indicate the position of the in situ trace elements.

b. Partially enlarged photo of fig. a.

c. Partial enlargement photo of picture $b$.

d Partial enlarged photo of Figure c.

e Standard sample of pyrite from the State Key Laboratory of Continental Dynamics, Northwest University.

f Partial enlarged photo of the red frame in picture a.

g Backscattered photo of picture a, at $130 \times$ times magnification.

$\mathrm{h}$ Partial enlargement photo of picture $i$.

i Partially enlarged photo in the red box at the right of picture a. 


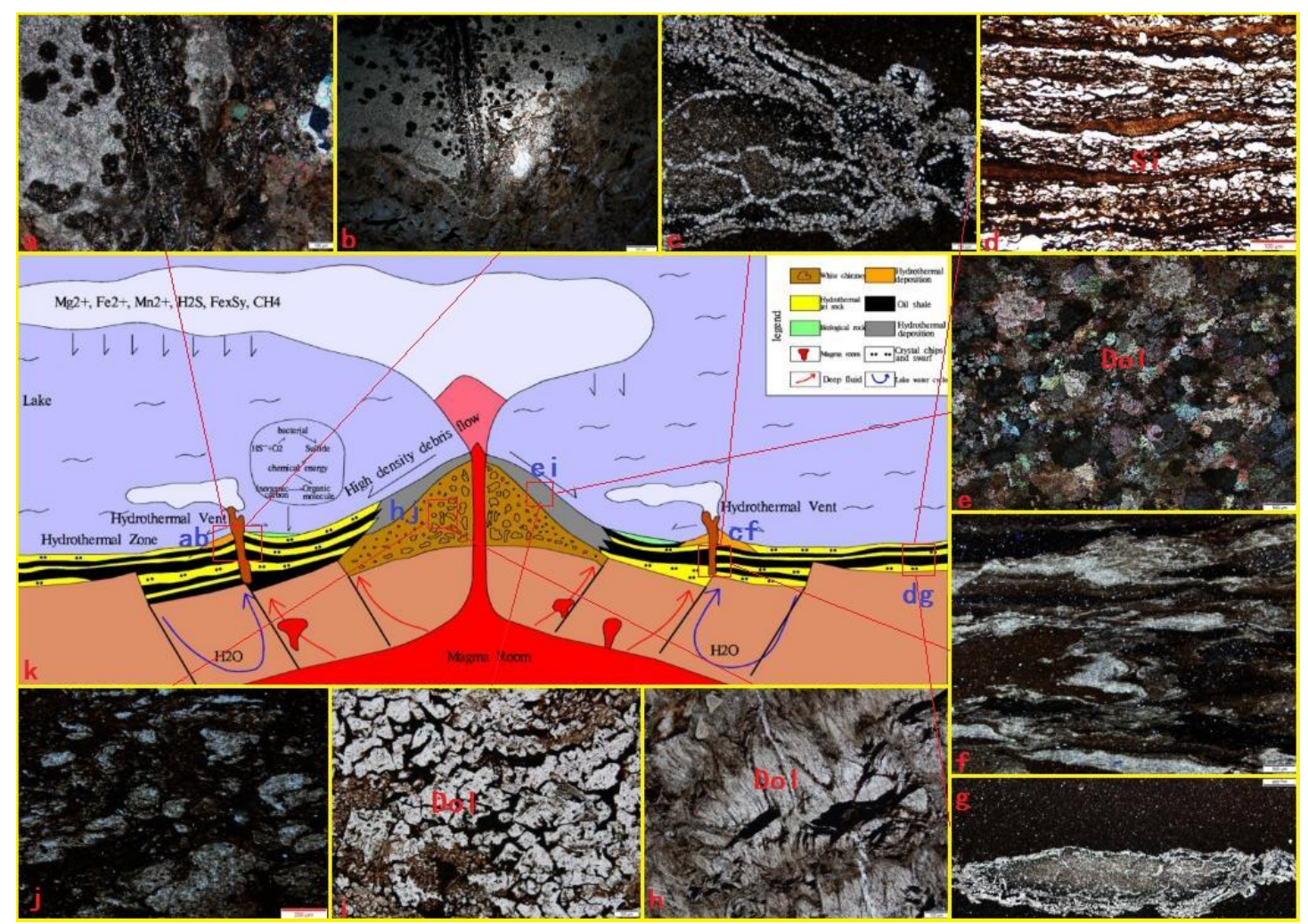

Fig. 5 Palaeo-hydrothermal nozzle formation mode

a Palaeo-thermal vent channel, filled with pyrite + iron dolomite + anhydrite, where the surrounding rock is dolomite, at $10 \times$ times magnification, with orthogonal light.

b Hydrothermal channel, at $10 \times$ times magnification, with orthogonal light.

c Hydrothermal fluid, at $10 \times$ times magnification, with orthogonal light.

d Siliceous rock, at $2.5 \times$ times magnification, with orthogonal light.

e Dolomite, at $10 \times$ times magnification, with orthogonal light.

f Reticular crack of the bedrock, filled with dolomite, at $2.5 \times$ times magnification, with orthogonal light.

g Distal deposition of the hydrothermal nozzle, at $10 \times$ times magnification, with orthogonal light.

h. Radial structure near the nozzle, at $10 \times$ times magnification, with orthogonal light. i. Iron dolomite near the spout, at $10 \times$ times magnification, with orthogonal light.

j Analcite, at $10 \times$ times magnification, with orthogonal light.

$\mathrm{k}$ Ideal pattern of hydrothermal vents. 


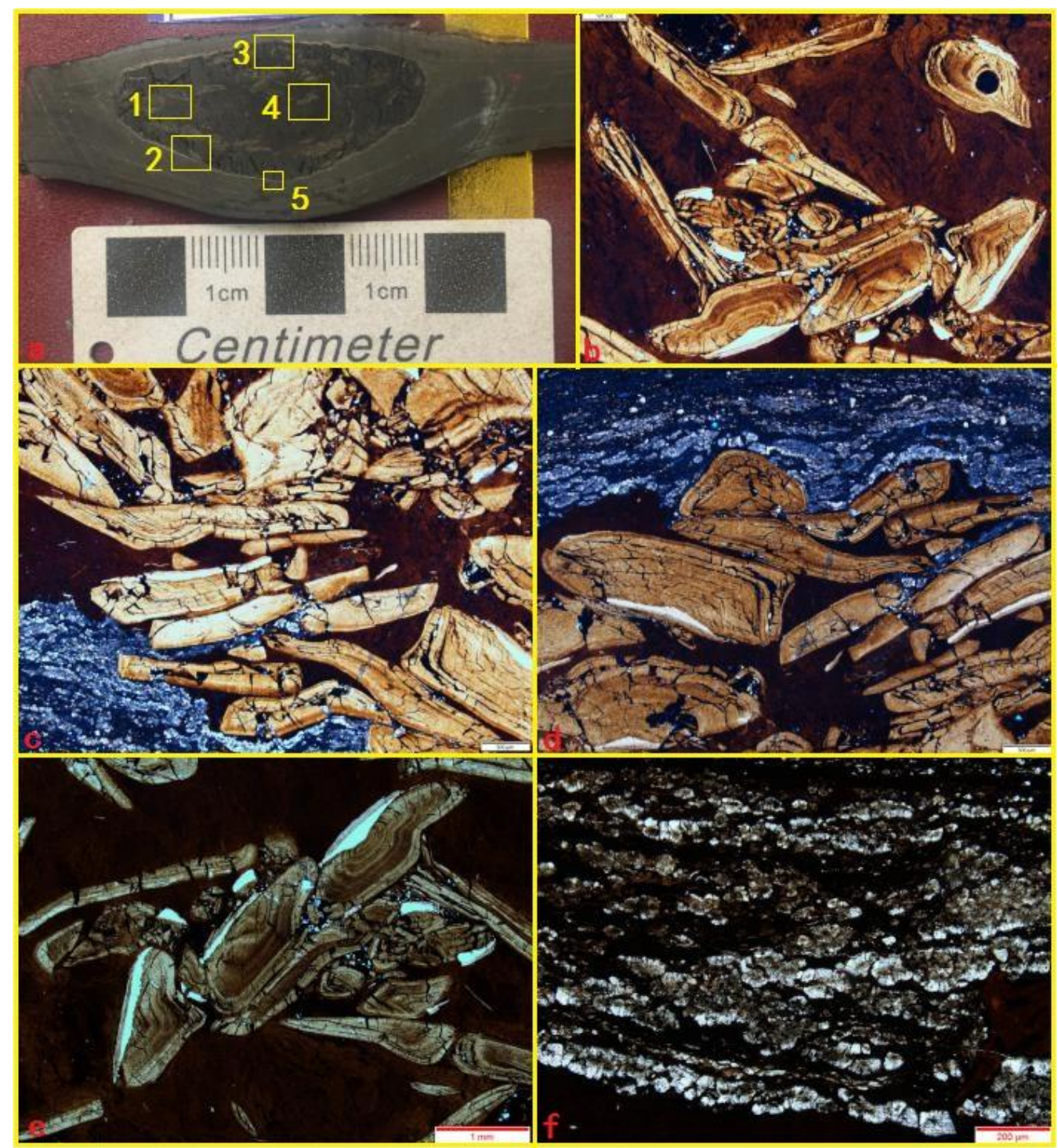

Fig. 6 Hydrothermal biocharacteristics of the Chang 7 Formation of the Triassic Yanchang Formation in the Ordos Basin

a: Cross section of sample BWZ-18-2 cod fossil, $4.2 \mathrm{~cm} \times 2.1 \mathrm{~cm}$. Rich fish scales and fish bone fossils are visible. The surrounding rocks are hydrothermal sedimentary rocks. Enlarged photo of yellow box No. 2 in Figure

b. Fish bone fossils, hard shells of fossils are broken, probably caused by hydrothermal eruption, $\times 2.5$ times, orthogonal light Enlarged photo of the yellow box No. 1 in Figure

c. The upper part is a fish bone fossil, and the lower part is the iron dolomite stratum, $\times 2.5$ times, orthogonal light.

d.The enlarged yellow box No. 3 in Figure a. The hard shell of the fossil is broken. The surrounding rock is dolomite, $\times 2.5$ times, orthogonal light.

e.Enlarged photo of yellow box No. 4 in e, a, fossil, $\times 2.5$ times, orthogonal light f.Enlarged photo of yellow box No. 5 in Figure a, iron dolomite, $\times 5$ times, orthogonal light 